\title{
O CÓDIGO DE DEFESA DO CONSUMIDOR NO SISTEMA SÓCIO- ECONÔMICO BRASILEIRO
}

\author{
Ada Pellegrini Grinover \\ Professora Titular do Departamento de Direito Processual da \\ Faculdade de Direito da Universidade de São Paulo
}

\begin{abstract}
Resumo:
Após tratar do caráter preventivo do Direito do Consumidor e das fórmulas utilizadas para sua definição, afirmando-lhe a natureza sócioeconômica, o trabalho cuida da inserção constitucional da tutela do consumidor no Brasil, da opção pela codificação, dos modelos inspiradores do Código Brasileiro de Defesa do Consumidor de 11.09.1990 e de seu conteúdo - com normas de direito substancial (civil, comercial, penal e administrativo) e processual -, dando especial destaque à defesa do consumidor em juízo, mediante ações individuais e coletivas.
\end{abstract}

Abstract:

After defining the field of consumer's right, the author writes about this right in the Brazilian Constitution and the Consumer's Code, giving the essential ideas on the substantive and procedural guarantees, including the Brazilian Class Action.

Unitermos: Direito do Consumidor; Defesa do consumidor em juízo.

Sumário:

1 O Direito do Consumidor;

2 - O consumidor brasileiro na Constituição de 1988;

3 - O Código Brasileiro de Defesa do Consumidor;

4 A defesa do consumidor em juízo;

5 - Conclusões. 
1 - O Direito do Consumidor

Não é de hoje que existem direitos dos consumidores: há muito tempo os diversos sistemas jurídicos se preocupam com o comprador, o locatário, o segurado, o passageiro. Mas formulação bem mais recente tem o Direito do Consumidor, enquanto disciplina jurídica que, além de se formar e se justificar no relacionamento social entre os homens como acontece com qualquer ramo do Direito - exige para sua plenitude o relacionamento humano na sociedade de consumo.

O grande desenvolvimento econômico que caracterizou o período posterior à Segunda Guerra Mundial significou a massificação da produção e do comércio, levando a tecnologias sofisticadas e à ampliação dos mercados. ${ }^{1}$ Evidenciou-se, assim, a necessidade de tutela específica dos consumidores. Mas, enquanto nos Estados Unidos da América o aparecimento do Direito do Consumidor se processou a partir de uma perspectiva individualista e reparatória, com a proteção do indivíduo-consumidor para se alcançar depois o público-consumidor, na Europa a evolução ocorreu desde logo a partir do esforço de tutelar o público como um todo, sendo secundária a preocupação de reparar os danos sofridos individualmente pelos consumidores. ${ }^{2}$

Seja como for, em ambos os sistemas common law e civil law o Direito do Consumidor, que havia nascido como corpo legal de caráter eminentemente repressivo (penal e administrativo), foi aos poucos se transformando, em face de certas características do mercado: a velocidade de suas transformações, o surgimento diário de novas e mais complexas modalidades de negócios e tecnologias; a vulnerabilidade do consumidor, quer para evitar o dano, quer para buscar reparação; a natureza e dimensão dos acidentes de consumo, muitas vezes de difícil reparação. E hoje o Direito do Consumidor é fundamentalmente preventivo. ${ }^{3}$

1. Thomas Trumpy, Consumer protection and product liability: Europe and the EEC, in The North Carolina Journal of International Law and Commercial Regulation, v. II, n. 2, 1966, p. 321.

2. Trumpy, ob. cit., p. 322.

3. Antônio Herman Vasconcelos e Benjamin, O Direito do Consumidor, in Rev. do MP do Rio Grande do Sul, v. 1, n. 26, 1992, pp. 107-108. 
Como observa Herman Benjamin, ${ }^{4}$ essa característica preventiva do Direito do Consumidor, preponderante na nova disciplina, tem duas vertentes: uma é a de impedir que a fragmentação da relação de consumo cause prejuízos ao consumidor. Outra é a de prevenir que o conflito de consumo venha a enfraquecer o próprio mercado e, com ele, a ordem capitalista. Isso porque o Direito do Consumidor, assim como o Direito Econômico, é "uma ação voltada à preservação do mercado enquanto mecanismo de coordenação do processo econômico tendo em vista o interesse social". ${ }^{5}$

Assim sendo, o Direito do Consumidor não é apenas um corpo de normas de proteção direta ao consumidor, individualmente considerado. O Estado freqüentemente intervém com medidas de controle do comportamento que protegem um interesse abstrato dos consumidores, mesmo que para tanto aparentemente contrarie as aspirações imediatas de seus tutelados. É o que sucede, por exemplo, com o controle da produção e comercialização de álcool e tabaco, ou com a obrigatoriedade do uso de cintos de segurança em automóveis. ${ }^{6}$

Diante dessa complexidade, como foi percucientemente observado, ${ }^{7}$ não há uma definição a priori do Direito do Consumidor, nem se pode chegar a uma conceituação válida para todos os tempos. Definí-lo, ao contrário, pressupõe o perfeito entendimento da função de consumo com suas variantes históricas e da relação jurídica de consumo.

Ademais, existem três fórmulas para definir-se Direito do Consumidor: uma definição objetiva, uma definição teleológico-subjetiva, e outra mista. ${ }^{8}$ Na primeira, ressalta-se a idéia de relação jurídica de consumo. Na segunda, põem-se em destaque os sujeitos da relação, tutelando-se particularmente um deles, por sua vulnerabilidade. E a terceira, que supera as insuficiências das outras, conjuga o critério objetivo com o teleológico-subjetivo.
4. Benjamin, ob. e loc. cit.
5. Eros Roberto Grau, Elementos de Direito Econômico, p. 19.
6. Gérard Cas e Didier Ferrier, Traité de Droit de la Consommation, p. 2.
7. Benjamin, ob. cit., p. 105.
8. Idem, ibid. 
A definição mista, inegavelmente a melhor, conceitua assim Direito do Consumidor como o conjunto de princípios e normas jurídicas que protegem o consumidor na relação jurídica de consumo. ${ }^{9}$

Donde se depreende a natureza essencialmente sócio-econômica do Direito do Consumidor, enquanto disciplina jurídica autônoma, cujos princípios, conceitos e instrumentos incidem profundamente nas relações entre consumidores e fornecedores, moldando e aperfeiçoando o mercado.

2 - O consumidor brasileiro na Constituição de 1988

A Constituição brasileira de 1988 elevou a tutela do consumidor à estatura constitucional, inserindo-a entre os direitos fundamentais e entre os princípios gerais da ordem econômica.

$\mathrm{O}$ art. $5^{\circ}$ da Constituição Federal, dedicado aos direitos e deveres individuais e coletivos, estabelece, no inc. XXXII, caber ao Estado a promoção da defesa do consumidor, nos termos da lei.

No capítulo atinente aos princípios gerais da ordem econômica, $o$ art. 170 ao rezar que "a ordem econômica, fundada na valorização do trabalho humano e na livre iniciativa, tem por fim assegurar a todos existência digna, conforme os ditames da justiça social" determina a observância de princípios fundamentais, entre os quais se inscreve, no inc. $\mathrm{V}$, a defesa do consumidor.

Mais especificamente, o art. 150, que trata das limitações do poder de tributar por parte do Poder Público no âmbito da União, Estados, Distrito Federal e Municípios, estabelece em seu $\S 5^{\circ}$ que "a lei determinará medidas para que os consumidores sejam esclarecidos acerca dos impostos que incidam sobre mercadorias e serviços"; e o inc. II do art. 175, aludindo aos serviços públicos prestados por intermédio de concessão ou permissão do Poder Público, determina no parágrafo único que a lei disporá sobre "os direitos dos usuários".

Finalmente, o art. 48 das Disposições Constitucionais Transitórias assinalou ao Congresso Nacional o prazo de 120 dias, a contar da promulgação da Constituição, para a elaboração do Código de Defesa do Consumidor.

9. Idem, p. 106. 
Deve-se dizer, ainda, que as generosas promessas constitucionais encontraram concretitude pela promulgação da Lei n. 8.078, de 11 de setembro de 1990 - o Código de Defesa do Consumidor, que entrou em vigor em março de 1991.

\section{3 - O Código Brasileiro de Defesa do Consumidor}

O texto constitucional reconheceu expressamente que o consumidor não pode ser adequadamente protegido apenas na base de um modelo privado (autoregulamentação, convenções coletivas de consumo, boicote), e nem mesmo por leis esparsas, muitas vezes contraditórias ou lacunosas. $\mathrm{O}$ constituinte brasileiro adotou expressamente a idéia da codificação, na trilha da melhor doutrina estrangeira, reconhecendo a necessidade de um arcabouço geral para o regramento do mercado de consumo. ${ }^{10}$

Com toda a razão, porquanto muitos são os benefícios da codificação que, além de permitir a reforma do direito vigente, apresenta diversas vantagens. Entre estas ressalta o fato de a sistematização da matéria dar coerência e homogeneidade a seu conteúdo, de modo a simplificar e esclarecer o regramento legal, favorecendo de uma maneira geral os destinatários e os aplicadores da norma e possibilitando a visão de conjunto e a própria autonomia da disciplina. ${ }^{11} \mathrm{~A}$ codificação supera, assim, crítica comum na Europa, onde se põe de manifesto o defeito da carência de uniformidade das normas de consumo, o que acaba por caracterizar o Direito do Consumidor muito mais como um fundo que ainda deve ser colocado em ordem. ${ }^{12}$

O Código, como não podia deixar de ser, foi buscar sua inspiração em modelos estrangeiros, mas os seus redatores tomaram a precaução de evitar, a todo custo, a mera transcrição de textos alienígenas, na conviç̧ão de que o Brasil - e seu mercado de consumo tem peculiaridades e problemas próprios. Tanto assim que

10. Na verdade, o Código foi votado na qualidade de lei apenas para escapar de iter legislativo mais formalista. Mas, não-obstante a denominação de lei, não há dúvidas de que se está diante de um código, e não-só pelo mandamento constitucional, mas sobretudo tendo em vista seu caráter sistemático. Tanto assim que no próprio diploma legal freqüente é o uso do vocábulo "código"

11. Ada Pellegrini Grinover e Antônio Herman de Vasconcellos e Benjamin, Introdução ao Código Brasileiro do Consumidor comentado pelos autores do Anteprojeto, Rio, Forense Universitária, 1995, p. 9.

12. Denise Baumann, Droit de la Consommation, p. 2. 
inúmeros dispositivos, de tão-adaptados à nossa realidade, se mostram arredios a qualquer tentativa de comparação com modelos estrangeiros. ${ }^{13}$

Apesar disso, é possível identificar-se em certas disposições do Código a influência de outros ordenamentos. $\mathrm{Na}$ origem dos direitos básicos dos consumidores está a Resolução n. 39/248, de 9 de abril de 1985, da Assembléia Geral da Organização das Nações Unidas. Mas a maior influência do Código veio do Projet de Code da la Consummation francês, redigido sob a presidência do Professor Jean Calais-Auloy. Importantes para a elaboração do Código foram também as leis gerais da Espanha (Ley General para la Defensa de los Consumidores y Usuários, Lei n. 26/1984), de Portugal (Lei n. 29/81, de 22 de agosto), do México (Ley Federal de Protección al Consumidor, de 5 de fevereiro de 1976) e de Quebec (Loi sur la Protection du Consummateur, promulgada em 1979).

Sob o ponto de vista mais específico de algumas de suas matérias, o Código buscou inspiração, fundamentalmente, no Direito comunitário europeu (Diretivas $84 / 450$, sobre publicidade, e $85 / 374$, sobre responsabilidade civil por acidentes de consumo). Para a formulação de regras sobre o controle das cláusulas gerais dos contratos, serviram-se os redatores do Código brasileiro das legislações de Portugal (Decreto-lei n. 446/85, de 25 de outubro) e da Alemanha (Gesetz zur Regelung des Rechts der Allgemeinen Gsechaftsbedingungen-AGB Gesetz, de 9 de dezembro de 1976).

A influência do Direito norte-americano foi dupla. Indireta, uma vez que as regras européias de tutela do consumidor mais atuais estão calcadas nos cases e statutes americanos. E direta, através da análise atenta do sistema legal de proteção ao consumidor dos Estados Unidos, em que foram particularmente úteis o Federal Trade Commission Act, o Truth in Lending Act, o Fair Credit Reporting Act e o Fair Debt Collection Practices Act. ${ }^{14} \mathrm{Na}$ parte processual atinente às ações coletivas, embora buscando-se sempre formulações que se adaptassem às peculiaridades brasileiras, não se descurou do estudo das class actions das Federal Rules de 1966.

O resultado disso tudo foi um Código que apresenta estrutura e conteúdo modernos, em sintonia com a realidade brasileira.

O Título I ("Dos direitos do consumidor") contém sete Capítulos, que vão desde as "disposições gerais" (Cap. I), "a política nacional das relações de

13. Grinover e Benjamin, ob. cit., p. 10.

14. Id., ob. cit., p. 10. 
consumo" (Cap. II) e "os direitos básicos do consumidor" (Cap. III), passando pela "qualidade de produtos e serviços, prevenção e reparação dos danos (Cap. IV), pelas "práticas comerciais" (Cap. V. compreendendo a oferta, a publicidade, as práticas abusivas, a cobrança de dívidas, os bancos e cadastros dos consumidores), pela "proteção contratual" (Cap. VI, tratando das cláusulas abusivas e dos contratos de adesão), para chegar às "sanções administrativas" (Cap. VII). O Título II cuida das "infrações penais". O Título III, da "defesa do consumidor em juízo" O "sistema nacional de defesa do consumidor" é o objeto do Título IV, enquanto o Título V versa sobre a "convenção coletiva de consumo" E finalmente o Título VI cuida das "disposições finais"

Vê-se daí que o Código contém normas de Direito substancial (civil, comercial, penal, administrativo) e de Direito processual, pondo de relevo o nítido caráter multidisciplinar do Direito do Consumidor. ${ }^{15}$

Entre suas principais inovações, cabe ressaltar as seguintes: formulação de um conceito amplo de fornecedor, incluindo, a um só tempo, todos os agentes econômicos que atuam, direta ou indiretamente, no mercado de consumo, abrangendo inclusive as operações de crédito e securitárias; um elenco de direitos básicos dos consumidores com os respectivos instrumentos de implementação; proteção contra todos os desvios de quantidade e qualidade (vícios de qualidade por insegurança e vícios de qualidade por inadequação); melhoria do regime dos prazos de decadência e prescrição; ampliação das hipóteses de desconsideração da personalidade jurídica das empresas; regramento do marketing (oferta e publicidade); controle das práticas e cláusulas abusivas, bancos de dados e cobrança de dívidas de consumo; introdução de um sistema sancionatório administrativo e penal; facilitação do acesso à Justiça do consumidor; incentivo à composição privada entre consumidores e fornecedores, inclusive pela previsão de convenções coletivas de consumo. ${ }^{16}$

Pode-se assim dizer, sem nenhum favor, que o Código projeta o Brasil numa posição de vanguarda com relação ao Direito do Consumidor. Os primeiros resultados de sua aplicação já são alviçareiros, mas ainda é preciso implementar cada

15. Sobre os dois sentidos da multidisciplinariedade do Direito do Consumidor (externa - com relação a ciências não-jurídicas e interna, porque, afora dos seus próprios, partilha de muitos princípios, conceitos, institutos e instrumentos de outras disciplinas jurídicas), v. Benjamin, $O$ Direito do Consumidor, cit., pp. 111-112.

16. Grinover e Benjamin, ob. cit., p. 11. 
vez mais suas normas e seus princípios, na busca de um mercado de consumo cada vez mais justo e equilibrado.

\section{4 - A defesa do consumidor em juízo}

A denominação do Título III Da defesa do consumidor em juízo coaduna-se com o espírito do Código, todo permeado pela idéia da vulnerabilidade do consumidor, devendo ser entendida em sentido amplo: o Título não compreende apenas a defesa processual stricto sensu, com as exceções opostas pelo consumidor, mas sim toda e qualquer atividade por este desenvolvida em juízo, tanto na posição de réu, quanto na de autor, a título individual ou pelos entes legitimados às ações coletivas. Trata-se, portanto, da tutela judiciária dos direitos e interesses do consumidor. ${ }^{17}$

Nas palavras lapidares de Kazuo Watanabe, ${ }^{18}$ as disposições contidas no Título põem bem à mostra a preocupação do legislador pela instrumentalidade substancial e maior efetividade do processo $^{19}$ e também pela sua adequação à nova realidade sócio-econômica, marcada profundamente pela economia de massa. ${ }^{20}$

Tudo isso, aliado ao esforço para diminuir os entraves que se antepõem ao acesso do consumidor à justiça e à ordem jurídica justa, ${ }^{21}$ demandava

17. Com esta expressão, não se quer aderir à teoria da ação como direito concreto (direito à sentença favorável), mas se quer expressar a idéia de acesso à justiça, no seu sentido mais amplo: sobre a teoria da ação como direito concreto, v. Cintra, Grinover \& Dinamarco, Teoria Geral do Processo, $11^{a}$ ed., São Paulo, Revista dos Tribunais, 1995, ns. 8 e 35. p. 489.

18. Kazuo Watanabe, Disposições Gerais, in O Código Brasileiro de Defesa do Consumidor, cit.,

19. Ver, no Brasil, Cândido Dinamarco, A instrumentalidade do processo, Revista dos Tribunais, São Paulo, 1987; José Carlos Barbosa Moreira, Notas sobre o problema da "efetividade" do processo, in Temas de Direito Processual, $3^{\mathrm{a}}$ série, Saraiva, 1984, pp. 27-42 e Tendências modernas do direito processual civil, in ob. cit., pp. 1-13; Kazuo Watanabe, Da cognição no processo civil, São Paulo, Revista dos Tribunais, 1987, pp. 15-25.

20. Mauro Cappelletti, Formazioni sociali e interessi di gruppo davanti alla giustizia civile, in Riv. Dir. Proc., 1975, pp. 361-402; Kazuo Watanabe, Acesso à Justiça e sociedade contemporânea, in Participação e Processo, coord. de Ada Pellegrini Grinover, Cândido Dinamarco e Kazuo Watanabe, Revista dos Tribunais, 1988, pp. 128-135; Ada Pellegrini Grinover, A tutela jurisdicional dos interesses difusos, in Novas Tendências do Direito Processual, Rio, Forense Universitária, 1990, pp. 137-143.

21. Ver, principalmente, a monumental obra de Mauro Cappelletti et alii, Access to Justice, Milão, Giuffrè, 1978, 6 volumes; ver também, de Cappelletti, Ascesso alla giustizia come programa di 
que se atuasse em profundidade. Exigia-se, de um lado, o fortalecimento da posição do consumidor em juízo - até agora pulverizada, isolada, enfraquecida perante a parte contrária que não é, como ele, um litigante meramente eventual -, postulando um novo enfoque de par condicio e do equilíbrio das partes, que não fossem garantidos no plano meramente formal; e, de outro lado, fazia-se necessária a criação de novas técnicas que, ampliando o arsenal de ações coletivas previstas pelo ordenamento, realmente representassem a desobstrução do acesso à justiça e o tratamento coletivo de pretensões individuais que isolada e fragmentariamente poucas condições teriam de adequada condução.

Para tanto, a parte processual do Código atua em duas vertentes: na das ações individuais e das ações coletivas. No campo das primeiras, a lei opera por intermédio de diversas normas, como as que contemplam a possibilidade de determinação da competência pelo domicílio do consumidor autor (art. 101, I); a vedação da denunciação da lide e um novo tipo de chamamento ao processo, em determinadas hipóteses (arts. 88 e 101, II); a previsão de adequada e efetiva tutela jurisdicional por intermédio de todo e qualquer tipo de ação (art. 83); a nova configuração da tutela específica, nas ações que tenham por objeto o cumprimento de obrigação de fazer ou não-fazer (art. 84); a extensão subjetiva da coisa julgada erga omnes, mas, em alguns casos, apenas para beneficiar as pretensões individuais (art. 103), etc. Outras regras, situadas fora do Título, complementam esse reforço de tutela, como ocorre, por exemplo, com a inversão, ope judicis, do ônus da prova em favor do consumidor (art. $6^{\circ}$, inc. VIII), com a implementação dos juizados de pequenas causas (art. $5^{\circ}$. inc. IV), com a assistência jurídica integral e gratuita ao consumidor carente (art. $5^{\circ}$ inc. I), com o habeas data em favor do consumidor (art. $\left.43, \S 4^{\circ}\right)$.

$\mathrm{Na}$ vertente das ações coletivas, amplia-se e especifica-se a tutela aos bens dos consumidores, indivisivelmente considerados, por intermédio das categorias dos interesses difusos e dos interesses coletivos (art. 81, I e II); cria-se uma nova ação, para o tratamento coletivo da reparação dos danos pessoalmente sofridos (art. 81, III e Cap. II do Título III), sem prejuízo da eventual fluid recovery (art. 100); aperfeiçoam-se as regras de legitimação e de dispensa de custas e de honorários advocatícios da Lei n. 7.347, de 24 de julho de 1985 a denominada lei

riforma e come metodo di pensiero, in Riv. Dir. Proc., 1982. No Brasil, ver sobretudo Kazuo Watanabe, Acesso à justiça e sociedade moderna, cit., pp. 128 e ss. 
da ação civil pública - (art. 87); dá-se novo tratamento à coisa julgada, quer no que diz com seus limites subjetivos, quer no que tange à ampliação do objeto do processo coletivo, para favorecer as pretensões individuais (art. 103); regula-se a litispendência (art. 104); amplia-se, enfim - fora do Título III a abrangência da referida Lei n. 7.347/85, para que a tutela desta se harmonize e se inteire com a do Código de Defesa do Consumidor (arts. 109 usque 117).

Tudo, enfim, dentro da óptica da necessária reestruturação dos esquemas processuais clássicos, para sua adaptação aos conflitos emergentes, próprios de uma sociedade de massa, de que os decorrentes das relações de consumo representam um ponto nodal. E tudo, ainda, dentro da idéia maior, já esboçada há mais de três décadas, segundo a qual a chamada crise do direito talvez apenas encobrisse "a dificuldade de dominar com categorias jurídicas substancialmente précapitalistas a fenomenologia de uma sociedade industrial" ${ }^{22}$

\section{5 - Conclusões}

Vê-se daí a relevância social de um diploma legislativo que vai influir diretamente na realidade econômica das relações de consumo.

Como bem observou Kazuo Watanabe, ${ }^{23}$ as normas materiais mais severas e mais apropriadas à regulação das relações de consumo certamente influirão decisivamente na redução dos conflitos de interesses a níveis mais aceitáveis; e, por isso mesmo, em que pese a maior facilitação do acesso à Justiça, o número de demandas, com o correr do tempo, será inferior ao que é esperado pelos mais céticos e críticos da nova legislação. Mas, nota ainda o Autor, para que isto realmente ocorra é necessário que a própria sociedade os consumidores e fornecedores de um lado e o Estado do outro - aceite e efetivamente ponha em prática os objetivos estabelecidos no Código. Controle de qualidade e de segurança dos produtos e serviços pelos próprios fornecedores, maior educação e informação dos fornecedores e consumidores quanto a seus direitos e deveres, coibição e repressão mais eficazes, em nível administrativo e criminal, de todas as formas de abuso, fortalecimento dos consumidores pela criação e desenvolvimento de associações representativas,

22. Tullio Ascarelli, Economia di massa e statistica giudiziaria, in Saggi di diritto commerciale, Milão, Giuffrè, 1955, p. 525.

23. Kazuo Watanabe, Disposições gerais cit., p. 496. 
organização dos mecanismos alternativos, oficiais e privados, de solução de conflitos de consumo (art. $4^{\circ} \mathrm{e}$ incisos), são algumas das providências objetivadas pelo legislador para que haja maior harmonia entre os atores que participam das relações de consumo.

E conclui Watanabe com uma última advertência: "de nada adiantará tudo isso, porém, sem que uma nova mentalidade se forme e através dela se construa uma sociedade menos individualista e egoista, mais participativa $e$ solidária" $^{24}$

O certo é que o Código aí está, em pleno vigor, já se tendo demonstrado instrumento hábil para os fins objetivados. $\mathrm{O}$ resto caberá a todos nós, enquanto membros de uma sociedade que se quer mais justa e equilibrada.

São Paulo, junho de 1996.

24. Id., ibid. 